DOI: 10.20472/IAC.2018.040.046

MRINAL MUSIB

National University of Singapore, Singapore

\title{
TECHNOLOGY-DRIVEN NOVEL STRATEGIES TO DECREASE ATTRITION RATES IN MASSIVE OPEN ONLINE COURSES (MOOC'S)
}

\begin{abstract}
:
Massive Open Online Courses (MOOCs) are rather a new phenomenon that has been possible due to the introduction and integration of technology into education to attain various learning objectives. Over the last 10 to 15 years MOOC's have evolved at a phenomenal pace and are presently being offered by various commercial platforms such as Udacity, Edx and Coursera, and are being offered by expert faculty members from several leading educational institutions and universities. The initial objective of MOOC's has been to make quality study materials accessible to anyone in the world at little or no costs, who has access to internet. In spite of the general acceptability and affordability of such novel platforms, their completion rate remains very low and is a huge concern. Typically $80-90 \%$ of the initially registered students eventually drop out due to various reasons. In this work we develop a four-pronged strategy on a Support-Trend-Expenses-Payout (STEP's) that educators and MOOC developers alike may adopt and implement to stem and decrease this high dropout rates seen in MOOCs.
\end{abstract}

\section{Keywords:}

MOOCs, drop out rates, innovative pedagogy, learning objectives 